\title{
LIDERANÇA: O QUE PENSAM EXECUTIVOS BRASILEIROS SOBRE O TEMA?
}

\begin{abstract}
ANDERSON DE SOUZA SANT"ANNA
Doutor em Administração pela Faculdade de Ciências Econômicas da Universidade Federal de Minas Gerais (UFMG).

Professor do Departamento de Administração da Fundação Dom Cabral (FDC). Avenida Princesa Diana, 760, Alphaville Lagoa dos Ingleses, Nova Lima - MG - Brasil - CEP 34000-000 E-mail: anderson@fdc.org.br

MARLY SOREL CAMPOS Mestre em Engenharia de Produção pela Faculdade de Engenharia da Universidade Federal de Santa Catarina (UFSC). Professora do Departamento de Administração da Fundação Dom Cabral (FDC). Avenida Princesa Diana, 760, Alphaville Lagoa dos Ingleses, Nova Lima - MG - Brasil - CEP 34000-000 E-mail:msorel@fdc.org.br

SAMIR LÓTFI

Mestre em Administração pela Faculdade de Economia e Administração da Universidade de São Paulo (USP). Professor do Departamento de Administração da Fundação Dom Cabral (FDC). Avenida Princesa Diana, 760, Alphaville Lagoa dos Ingleses, Nova Lima - MG - Brasil - CEP 34000-000 E-mail: samir@fdc.org.br
\end{abstract}




\section{RESUMO}

Este artigo tem como objetivo central apresentar resultados de estudo destinado a investigar as principais questões e desafios em torno da temática da liderança e seu desenvolvimento, na contemporaneidade, segundo a perspectiva de altos executivos de grandes empresas brasileiras. Considerando tal propósito, seus objetivos específicos podem ser assim descritos: I. investigar sentidos atribuídos e estilos de liderança articulados à vivência e prática dos executivos investigados; 2. investigar temas-chave ao desenvolvimento de lideranças no atual contexto dos negócios e das organizações; 3. identificar tendências, novos temas e desafios em torno da temática da liderança, no contemporâneo. Como referencial teórico cabe salientar revisão de literatura envolvendo descrição evolutiva dos estudos sobre a temática, com destaque para as principais correntes e abordagens teórico-metodológico-conceituais. Em termos metodológicos, a pesquisa que subsidiou os resultados deste estudo pode ser caracterizada como de natureza qualitativa e caráter descritivo, tendo seus dados primários derivados de entrevistas semiestruturadas e em profundidade realizadas com I3 altos executivos de grandes corporações, nacionais e internacionais, situadas nos estados de São Paulo e Minas Gerais. Após tratamento dos dados, com o auxílio do software de tratamento qualitativo NVivo 8, foi possível agrupar os principais temas e desafios identificados em torno da liderança em três temas-chave: Sentidos, Competências, Estilos e Desafios associados à Liderança no Contemporâneo; Desenvolvimento de Lideranças; Liderança e Contexto Capacitante. O estudo possibilitou, também, identificar atributos de competência e estilos de liderança requeridos como respostas ao atual contexto dos negócios e das organizações, segundo a perspectiva dos executivos entrevistados. Concomitantemente, foi possível constatar novos desafios e preocupações em relação à temática da liderança, como, por exemplo, lidar com as novas gerações - em especial a chamada Geração Yque, em breve, deverão assumir posições-chave nas organizações, em decorrência da aposentadoria dos Baby Boomers. Em suma, os achados permitem, a partir da perspectiva dos próprios atores diretamente envolvidos na problemática da 
liderança, no contexto empresarial, a emergência de questões e desafios a serem contemplados em novas agendas de desenvolvimento e linhas de pesquisa sobre o tema.

\section{PALAVRAS-CHAVE}

Liderança; Desenvolvimento de Liderança; Desenvolvimento de Executivos; Estilos de Liderança; Competências em Liderança.

\section{INTRODUÇÃO}

A temática da liderança tem sido objeto de inúmeros estudos e pesquisas, notadamente quando o crescimento e a expansão geográfica das organizações passam a requerer, cada vez mais, estratégias diferenciadas para a conquista e adesão das pessoas aos objetivos corporativos. Tais estudos acabaram por resultar no desenvolvimento de uma série de teorias e abordagens, as quais buscam melhor compreender o fenômeno, assim como propor formas mais efetivas de seu desenvolvimento.

Neste século, ainda como desdobramento da ruptura do chamado "Ciclo Virtuoso do Fordismo", em meados dos anos I970, registra-se a emergência de novas arquiteturas organizacionais, com diferentes estruturas e vínculos de trabalho. Em paralelo, os crescentes saltos tecnológicos têm propiciado conexões, em tempo real, entre pessoas e empresas, em diferentes partes do planeta, com interações multiculturais distintas. No âmbito político-social, constata-se um aumento do ceticismo das pessoas em relação ao futuro e aos empregos, assim como intensificação dos níveis de estresse, agravados pelo aumento das horas de trabalho, pela competição e insegurança nos grandes centros urbanos (GAULEJAC, 2007).

Nesse contexto, vários questionamentos têm sido endereçados aos líderes em geral e, em particular, àqueles de organizações empresariais: "Como mobilizar pessoas em um ambiente tenso e tumultuado por contínuas mudanças?”, "Como liderar pessoas 'relutantes' que dispõem de informações em tempo real?”, "Como liderar em um terreno competitivo em que os talentos são disputados tanto por concorrentes quanto por parceiros?", "Como promover ambientes internos de entusiasmo e de desenvolvimento contínuo?", "Como conquistar credibilidade pessoal e promover compromisso dos diversos membros da equipe?”.

Tendo por base tais problemáticas, este trabalho tem como propósito central apresentar resultados de estudo desenvolvido por grupo multidisciplinar 
e multi-institucional de pesquisa, reunido em torno do Núcleo Vale de Desenvolvimento de Liderança, da Fundação Dom Cabral, que, sob a coordenação do professor Anderson de Souza Sant'Anna, tem se dedicado a investigar questões e desafios associados à temática da liderança e seu desenvolvimento, no contemporâneo. Dentre as iniciativas desenvolvidas no âmbito desse núcleo, inserem-se pesquisas, laboratórios e grupos de discussão, envolvendo acadêmicos, executivos e especialistas de diferentes instituições, áreas do conhecimento, campos de atuação e países. Neste artigo, são apresentados resultados de levantamento empírico de dados realizado com altos executivos de grandes empresas atuantes no Brasil, com o intuito de investigar suas percepções quanto às principais questões e desafios atuais da liderança e seu desenvolvimento. Vale salientar a compreensão, para fins deste estudo, de questões e desafios da liderança, como aspectos internos e externos ao ambiente organizacional que influenciam as práticas de gestão, assim como relações dessas instituições/organizações com os diferentes atores sociais intervenientes em sua atuação.

Considerando o objetivo central deste estudo, seus objetivos específicos podem ser assim descritos: I. investigar sentidos atribuídos e estilos de liderança articulados à vivência e prática dos executivos investigados; 2. investigar temas-chave associados ao desenvolvimento de lideranças no atual contexto dos negócios e das organizações; 3. identificar tendências, novos temas e desafios em torno da temática da liderança, no contemporâneo.

Como referencial teórico, cabe salientar revisão de literatura que busca abranger a evolução dos estudos sobre liderança, com destaque para as principais correntes e abordagens teórico-metodológico-conceituais desenvolvidas sobre o tema.

Em termos metodológicos, a pesquisa que subsidiou os resultados deste estudo pode ser caracterizada como de natureza qualitativa e caráter descritivo, tendo seus dados primários derivados de entrevistas semiestruturadas e em profundidade, realizadas com I3 altos executivos de grandes corporações, nacionais e internacionais, situadas nos estados de São Paulo e Minas Gerais. Para o tratamento dos dados optou-se pela abordagem qualitativa, por meio de análise de conteúdo por categoria, realizada a partir da transcrição de entrevistas semiestruturadas e em profundidade, tratadas com o auxílio do software NVivo 8.

No que tange à sua relevância, o estudo se justifica, em termos teóricos, ao ampliar a compreensão sobre o estágio, as questões e os desafios que marcam os estudos sobre a Liderança, no Brasil. Justifica-se, ainda, ao propiciar subsídios a problematizações que permitam o delineamento de novas perguntas, abordagens teórico-metodológicas e linhas de pesquisa, assim como novos desenhos de programas e disciplinas sobre o tema. 
Isso posto, apresenta-se, a seguir, uma revisão de literatura sobre o construto liderança, seguido de tópico abrangendo aspectos metodológicos da pesquisa. Na sequência, procede-se à descrição e análise dos dados obtidos. Finalmente, é apresentada uma síntese dos resultados e as principais conclusões do estudo.

\section{FUNDAMENTAÇÃO TEÓRICA}

\subsection{O MOVIMENTO EM TORNO DA LIDERANÇA}

A tentativa de compreender a liderança constitui uma antiga empreitada humana: Bass (I990) atribui aos egípcios, mais particularmente a Ptahhotep, o primeiro registro escrito sobre o tema, datado de 2300 a.C. Nesse escrito, a liderança deriva de algo transcendental ao ser humano e designa qualidades superiores. Em uma tentativa mais pragmática de entendimento do fenômeno, Maquiavel, em O príncipe (I513), descreve tipos de governo e formas como o líder deveria conduzir-se diante de "amigos", assim como procedimentos para se manter no poder.

Já no século XIX, de forma mais sistemática, os estudos se orientam à identificação de características e atributos de grandes personalidades, as quais deveriam servir de modelo e base para as ações de formação de novos líderes. Tais estudos acabaram por culminar na denominada Teoria dos Traços, que se concentra na construção de listagens de aspectos gerais de personalidade que, desenvolvidos, aumentariam o potencial da liderança (SETERS; FIELD, I990). Bergamini (I994) observa, no período entre as duas grandes guerras mundiais (I920-I950), ampla gama de estudos sob essa perspectiva. Com ênfase em aspectos de inteligência e personalidade, tais estudos visavam distinguir características do líder em uma perspectiva universalista, independentemente da situação e das variáveis a que se encontravam submetidos. Tal abordagem teórica, todavia, não viria a demonstrar consistência e consenso quanto a seus resultados (STODGILL, I974). Achados cumulativos revelariam a inexistência de tais traços universais (ROBBINS, 2002).

Diante disso, estudos seguintes, inicialmente capitaneados por Kurt Lewin, direcionaram-se à compreensão da dinâmica do comportamento dos líderes, por meio do estudo de indivíduos em posição de liderança. O pressuposto era que, conhecidos os comportamentos eficazes de liderança, poder-se-iam treinar pessoas para manifestarem tais comportamentos (BERGAMINI, I994; HORNER, I997).

Avançando nessa perspectiva, pesquisadores da Ohio University (Estados Unidos) realizaram inúmeras investigações buscando articular o desempenho 
de líderes com a eficácia empresarial. Dentre os resultados encontrados, verificou-se que parte das atividades do líder encontrava-se ligada a coisas ou tarefas, e outra parte, a pessoas, configurando-se duas predisposições ou dimensões distintas da liderança.

Por meio de estudos paralelos, na Universidade de Michigan, Likert (I96I) chegou a resultados semelhantes, propondo estilos de liderança denominados "orientação para o empregado" e "orientação para a produção". Para esse autor, uma maior eficácia estaria associada ao estilo de liderança que envolvesse as pessoas no processo decisório e promovesse maior satisfação e produtividade no trabalho, assumindo, dessa forma, notória inclinação para uma liderança "democrática" (BERGAMINI, I990).

Blake e Mouton (I964) operacionalizaram esses estudos em programa de treinamento gerencial e de desenvolvimento organizacional, por meio do clássico Grid Gerencial, o qual consiste em uma matriz em que se classificam os estilos de liderança segundo a orientação para pessoas e/ou para a produção, propondo-se que a maior eficácia se concentraria em líderes que conseguissem otimizar essas duas dimensões ("estilo 9,9"). Recebida com entusiasmo no meio empresarial, a abordagem foi, todavia, fortemente criticada pela ausência de fundamentação empírica.

Também com ênfase na realidade organizacional e em comportamentos e estilos de liderança, porém com uma sustentação teórica mais refinada, McGregor (I966) desenvolve as chamadas Teoria X e Y. Para o autor, as práticas dos líderes e gestores são baseadas em uma série de pressupostos e valores em relação à natureza humana, apresentando boa correlação com a realidade organizacional. Partindo do pressuposto de que as pessoas são competentes e criativas (Teoria Y), o autor propõe uma gestão que propiciasse espaço ao desenvolvimento individual e a ambientes mais participativos.

Ampliando essa perspectiva, os trabalhos de Fiedler (1967), bem como de Hersey e Blanchard (I969), apontam para o caráter contingencial da liderança, em que não apenas o líder, mas também os liderados e a situação são variáveis que determinam o processo da liderança.

Segundo Fiedler (1967), uma liderança orientada para tarefas seria mais eficaz em situações de baixa ou alta aceitação dos subordinados, enquanto, em casos de aceitação moderada, sugere-se uma gestão por relacionamentos. A questão passa a ser, portanto, identificar o estilo mais eficaz para uma determinada situação, em vez de o melhor estilo de liderar. Afinal, "o líder que se desempenha bem em um grupo ou sob um conjunto de condições pode não se sair bem em outros grupos, em outras tarefas ou sob outras condições" (FIEDLER, I967, p. I6).

Além das características de personalidade e de comportamentos orientados para tarefa ou para pessoas, Fiedler (I967) destaca outra variável importante no 
processo, por ele denominada de "favorabilidade", a qual se associa ao grau em que uma dada situação permite ao líder exercer seu controle ou influência sobre o grupo. Três aspectos parecem determinar se dada situação é favorável aos líderes: I. as relações pessoais entre ele e os membros do grupo (positivas, como lealdade e amizade, ou negativas, como falta de confiança e de abertura); 2. posição de poder, relacionada à posição hierárquica do líder - forte ou fraco - e sua condição de conferir recompensas ou punições; 3. natureza da tarefa, que pode ser estruturada ou não.

Observa-se, nessa abordagem, as primeiras considerações quanto a significativo fator interveniente no desempenho organizacional e, por conseguinte, de suas lideranças: o ambiente interno. Afinal, "caso se queira aumentar a eficácia organizacional e grupal, é preciso não só treinar mais eficazmente os líderes, mas também construir um ambiente organizacional no qual eles possam sair-se bem". Tal abordagem inclui, também, considerações quanto à motivação dos subordinados, na medida em que "o estilo de liderança apropriado será determinado pelas necessidades que os indivíduos procuram satisfazer” (BERGAMINI, I994).

Ainda no âmbito da teoria contingencial, outros modelos incorporam outros fatores à capacidade de influenciar e motivar os liderados, como a teoria caminho-objetivo (Path-goal), de House e Mitchell (I974). Segundo o modelo proposto por esses autores, o líder deve motivar seus liderados estimulando expectativas positivas em relação aos objetivos da organização e suas consequentes recompensas individuais. Os subordinados também precisam estar confiantes de que os caminhos pelos quais os líderes os guiam são os mais adequados. Assim, os fatores motivacionais dessa teoria apresentam-se associados à percepção dos liderados sobre suas recompensas, quando do alcance de metas (objetivos), bem como sua confiança de que os caminhos rumo a tal ganho são os que apresentam as maiores chances de sucesso (HOUSE, I97I). House (I97I) distingue, no mais, quatro tipos comportamentais de liderança: I. "liderança diretiva", quando o líder estipula aquilo que se espera do subordinado e dá orientações específicas de como chegar a isso, demarcando ritmos e padrões de desempenho; 2. "liderança de apoio", quando o comportamento do líder demonstra sua preocupação com o bem-estar do subordinado; 3. "liderança participativa", quando o líder não apenas consulta como solicita sugestões consideradas importantes no processo de tomada de decisões; 4. "liderança orientada para realização", quando coloca objetivos desafiadores, demonstrando confiança na responsabilidade e esforço pelos colaboradores. Seguindo um enfoque contingencial ou situacional, o líder irá adequar seu comportamento, conforme aspectos da tarefa e dos colaboradores (HOUSE; MITCHELL, I974).

No que se refere ao desenvolvimento da liderança, observa-se que essas teorias inspiraram diversos "pacotes" de treinamento de líderes. Entretanto, nenhu- 
ma avaliação comprovou seus resultados. Na realidade, em muitos casos, o que se viu foi uma tentativa de modificar pessoas, procurando transformá-las em grandes líderes (BERGAMINI, I994).

Não se deve, todavia, subestimar o valor das pesquisas sobre traços, comportamentos, estilos de liderança e motivos, no percurso para maior compreensão do processo de liderança, uma vez que, anteriormente, pouco havia de sistemático no campo de estudos sobre o tema. Tais abordagens, pelo menos, ofereceram uma descrição da figura do líder não se detendo, no entanto, de forma mais profunda e crítica a respeito de variáveis que poderiam afetar seu desempenho ou eficácia (FIEDLER, I967; BERGAMINI, I994).

Ressalva-se, também, que as teorias contingenciais, ao incluírem variável associada à situação, tiveram como premissa a inexistência de estilo de liderança universalmente válido, buscando associar fatores ligados aos liderados e situacionais à análise do fenômeno, apresentando, por conseguinte, maior abertura ao estudo da dinâmica da liderança.

Alguns críticos, todavia, mostram-se céticos quanto à aplicação das teorias contingenciais, em especial, ao conferirem ênfase à mudança das pessoas, esperando, desse modo, estabelecer estilos comportamentais que se diferenciam frente à multiplicidade de situações organizacionais:

O enfoque situacional sustenta que quase tudo seja flexível e possa adaptar-se às demandas das situações, incluindo o estilo dos gerentes. De maneira extrema, esse enfoque resulta em um comportamento no trabalho que foi polido, no qual o ator comporta-se de formas que podem não ser consistentes com a personalidade, os valores e a forma de pensar dessas pessoas (BADARACCO; ELLSWORTH, I989, p. 202).

Partindo de estudos de líderes políticos, James MacGregor Burns propicia uma nova perspectiva ao campo da liderança, notadamente, ao enfatizar a sensibilidade a pessoas como aspecto-chave da liderança. Burns, em essência, propõe uma teoria que engloba dois tipos de líderes: transformacionais e transacionais, a qual veio a ter grande influência em diversas abordagens desenvolvidas no final do século XX, dentre elas a de Bennis e Nanus (I988).

Para Burns, a liderança não se refere à ação de uma pessoa sobre outra, mas a um processo de influência de dupla direção, entre líder e seguidor. A liderança transacional se localiza em um intercâmbio entre líder e seguidores, com recompensas aos seguidores, por promoverem melhor desempenho nas tarefas. A troca pode ser de ordem econômica, política ou psicológica, mas sem ligação duradoura entre as partes. 
Já a liderança transformacional tem como referência a sensibilidade às próprias necessidades, bem como aos desejos e às expectativas dos demais, mesmo sem uma consciência clara, como afirma Burns (I978, p. 40): "Mas o processo fundamental, um pouco mais amplo, é, em larga escala, tornar consciente aquilo que permanece inconsciente em seus seguidores". O autor destaca, ainda, o caráter mútuo da interação ou influência:

[...] o líder transformacional procura motivos potenciais nos seguidores, no sentido de satisfazer necessidades de alto nível e assume o seguidor como pessoa total. O resultado da liderança transformacional é um relacionamento de estímulo mútuo e elevação que converte os seguidores em líderes e pode convertê-los em agentes morais (BURNS, I978, p. 4).

Bass e Avolio (I990) conduziram pesquisas que indicaram maior efetividade da liderança transformacional sobre a transacional: índices mais baixos de rotatividade, produtividade maior, além de maior satisfação dos funcionários.

Kouzes e Posner (I997), igualmente, calcaram-se no modelo transformacional de Burns, assim como na abordagem da liderança visionária, de Nanus (I992), ao proporem uma nova abordagem baseada em pesquisas regulares com centenas de líderes e seguidores em organizações de diferentes portes. Nesse modelo, os autores reservam papel relevante tanto ao líder, quanto aos seguidores. Para eles, no relacionamento que se constrói entre as partes, busca-se uma melhoria da situação atual em direção ao alcance de uma visão. "Assim, definimos a liderança como a arte de mobilizar os outros para que estes queiram lutar por aspirações compartilhadas" (KOUZES; POSNER, I997, p. 33).

Para Kouzes e Posner (I997), a ação do líder se pauta em ações e valores que incluem, dentre outros: I. desafiar o estabelecido, buscando oportunidades de inovar e melhorar; 2. inspirar uma visão compartilhada; 3. permitir que os outros ajam, incentivando a participação e promovendo a confiança e fortalecimento das pessoas; 4 . credibilidade, atuando como exemplo de prática de valores; 5 . reconhecimento das contribuições individuais e celebração regular das conquistas.

No âmbito das organizações do século XXI, o estudo do processo de liderança coloca em evidência a ampla diversidade e quantidade de variáveis a que se submete a figura do líder. Diante disso, novas abordagens têm sido propostas 56 visando conferir ao construto da liderança um caráter mais processual, multinível e multidimensional, mais afins à complexidade dos atuais ambientes de negócios e organizacionais.

Ilustrando tais perspectivas, Yammarino, Dansereau e Kennedy (200I, p. I52) propõem uma abordagem que compreende diversos níveis e dimensões de aná- 
lise. Mais precisamente, os autores destacam quatro níveis de análise do fenômeno da liderança: individual, líder-liderado, grupal e coletivo. Segundo eles, o nível individual (Person) compreende os fatores que explicariam as diferenças no modo de as pessoas se posicionarem perante o fenômeno da liderança. No nível da díade líder-seguidor (Dyad), destaca-se a distinção entre o líder e cada seguidor: "cada uma das relações interpessoais da díade é o única e não depende de outras relações no grupo ou time" (YAMMARINO; DANSEREAU; KENNEDY, 200I, p. I50). O nível do grupo (Group) refere-se ao tratamento do líder em relação à sua equipe considerada como uma unidade. No nível coletivo (Collective), por sua vez, encontra-se a noção de que o coletivo é formado por diversos grupos que se estruturam, hierarquicamente, em grupos cada vez maiores: "Essas coletividades são sistemas, nos quais grande número de pessoas está ligado umas às outras devido a um conjunto de expectativas partilhadas ou comuns".

O modelo incorpora, também, as dimensões: Fundamental Human Process, Leadership Core Process, Leadership Outcomes, Other Multi-Level Outcomes e Substitutes for Leadership, a qual contempla elementos que poderiam substituir a liderança como fator de intervenção para alcance dos objetivos organizacionais, tais como: a análise do cargo, pautado em conhecimentos, habilidades e atitudes; relações informais; grupos de trabalho que partilham responsabilidades e práticas de gestão que sustentem os valores, a filosofia e a missão da organização.

Refletir sobre as diversas variáveis da ação de liderança sistematizadas por Yammarino, Dansereau e Kennedy (200I) permite constatar que o desenvolvimento de liderança requer um esforço contínuo de autoconhecimento, de conhecimento das outras pessoas, do ambiente interno e da sociedade em seu entorno.

Relacionado a esse aspecto e na esteira dos recentes estudos sobre sustentabilidade e responsabilidade social, registra-se recente preocupação com os impactos da atuação do líder para além das fronteiras organizacionais e de seu desempenho específico, compreendendo os impactos de suas ações sobre diferentes stakeholders, assim como um entendimento mais amplo de como se organiza a dinâmica de forças que lhes conferem poder (SMITH et al., 2004).

Há que se salientar, também, a importância de abordagens, como a chamada Teoria da Troca entre Líder e Liderado (Teoria LMX), que, igualmente, visam dar mais destaque às relações entre líderes e liderados, a fim de ampliar a análise da liderança, incorporando perspectivas daqueles que são alvo da liderança. Resultante de pesquisas de natureza situacional, a Teoria LMX, de Dansereau, Graen e Haga (I975), se propõe a explicar como a natureza dos relacionamentos entre líderes e subordinados influencia o processo da liderança (HORNER, I997). A LMX desafia a suposição de que os líderes tratam seus seguidores de forma coletiva, usando um estilo comportamental médio. Segundo ela, os líderes desenvolvem relacionamentos distintos com cada um dos liderados, e tais relacionamentos 
evoluem para diferentes direções, por meio de uma série de trocas, destacando diferenças entre o líder e cada um de seus liderados (NORTHOUSE, 2004).

Por conseguinte, estudar o fenômeno liderança implica considerá-lo além do âmbito individual e empresarial. As perspectivas do indivíduo, do grupo e da sociedade se integram ao campo da liderança, como formas de compreendê-lo em suas várias facetas e interseções. Em decorrência, apresenta-se relevante o delineamento de novos enfoques teórico-metodológico-conceituais capazes de permitir uma compreensão mais ampla das múltiplas variáveis que afetam a liderança e que levem em consideração a trama que articula e explicita tais variáveis. Essa concepção orienta a realização deste estudo, que visa, sob uma perspectiva problematizadora, investigar as principais questões e desafios que marcam o estudo da liderança no contexto atual.

Delineado o contexto teórico-conceitual em que se situa este estudo, são apresentados, a seguir, os aspectos metodológicos da pesquisa que subsidiou seus resultados.

\section{ASPECTOS METODOLÓGICOS}

Este trabalho pode ser classificado como uma pesquisa descritivo-analítica. O estudo pode, também, ser caracterizado como uma pesquisa de campo, de caráter qualitativo.

Os dados primários consistiram em entrevistas semiestruturadas e em profundidade, realizadas com I3 ocupantes de posições estratégicas (diretores ou presidentes) em empresas de grande porte, nacionais e internacionais, localizadas em São Paulo e Minas Gerais. Todos os executivos possuem mais de I2 anos de experiência em cargos de gestão, sendo a quase totalidade deles do sexo masculino (I2 dos I3 entrevistados). Os entrevistados foram escolhidos por conveniência e por possibilidade de contribuição teórica, buscando-se executivos em posições-chave em empresas de diferentes setores: Brasken, Adler, Companhia Energética de Minas Gerais (Cemig), Suzano Papéis e Celulose S.A., Merial, Woodbridge, Villares Metals e Usiminas. Os sujeitos de pesquisa apresentam, portanto, características que se enquadram no escopo do estudo e nos requisitos necessários ao alcance de seus objetivos.

Cabe salientar que as entrevistas foram gravadas e transcritas para posterior análise, por meio da técnica de análise de conteúdo, por categoria. Esse procedimento busca avaliar material oriundo de diversas fontes, com o principal objetivo de sintetizar e analisar o material colhido, utilizando para isso, categorias (FLICK, 2009). O roteiro de entrevistas utilizado contemplou dez 
questões visando investigar aspectos, tais como: definição e entendimento acerca do construto liderança; desafios vivenciados pelos líderes na atualidade; recursos pessoais - habilidades, conhecimentos, atitudes, experiências - requeridos às lideranças ante os desafios e as demandas do atual e futuro contexto dos negócios e das organizações; liderança e formas de seu desenvolvimento; possibilidades e desafios quanto à construção de ambientes organizacionais favoráveis à liderança.

O tratamento dos dados coletados contou com auxílio do software de análise qualitativa de dados NVivo 8, seguindo o processo de codificação e categorização, conforme indicado por Flick (2009). Com o auxílio desse software, buscou-se, primeiramente, a geração exaustiva de categorias mutuamente exclusivas (MILES; HUBERMAN, I994), representadas por um conjunto de códigos referentes a diversas impressões, críticas e fatores convergentes sobre o tema. Desse conjunto de códigos, descritos como de primeira ordem, foram estabelecidas relações de proximidade, causa e efeito, o que possibilitou a identificação de categorias de segunda ordem, baseadas em descrições mais abrangentes (GIOIA; THOMAS, I996), as quais se constituíram nos principais temas (dimensões-chave) em liderança, segundo os pesquisados.

\section{APRESENTAÇÃO E ANÁLISE dos RESULTADOS}

Conforme mencionado no item anterior, por meio da análise do conjunto dos dados obtidos com os executivos pesquisados, foi possível agrupar as principais questões e desafios contemporâneos em torno da noção de liderança em três grandes temas (dimensões-chave): Sentidos, Competências, Estilos e Desafios da Liderança no Contemporâneo; Desenvolvimento de Lideranças para o Contexto Atual; Liderança e Contexto Capacitante.

\section{SENTIDOS, COMPETÊNCIAS, ESTILOS E DESAFIOS DA LIDERANÇA NO CONTEMPORÂNEO}

A primeira das categorias observadas diz respeito aos sentidos conferidos ao termo liderança, o que abrange atributos, estilos, funções e desafios ao seu exercício.

Os relatos revelam diversos atributos de competências associados à figura do líder no contexto atual. O Quadro I descreve os atributos mais amplamente enfatizados. 


\section{QUADRO I}

\section{ATRIBUTOS DE COMPETENCIAS ASSOCIADOS}

A FIGURA DO LÍDER NO CONTEXTO ATUAL

\begin{tabular}{|c|c|}
\hline $\begin{array}{l}\text { ATRIBUTOS DE } \\
\text { COMPETÊNCIA }\end{array}$ & RELATOS ASSOCIADOS \\
\hline $\begin{array}{l}\text { Capacidade } \\
\text { de assumir } \\
\text { responsabilidades }\end{array}$ & $\begin{array}{l}\text { "O líder tem a tendência de chamar a responsabilidade para si, ser um } \\
\text { pouco mais autocrático e tal, essa coisa toda. Isso é do perfil, nasce." }\end{array}$ \\
\hline Curiosidade & $\begin{array}{l}\text { "Ele [o líder] tem que ter como característica a curiosidade. Você pode } \\
\text { ter uma pessoa extremamente inteligente, extremamente racional, mas } \\
\text { se ele não tem curiosidade para entender ele nunca vai ser um líder." }\end{array}$ \\
\hline $\begin{array}{l}\text { Capacidade de } \\
\text { lidar com o erro }\end{array}$ & $\begin{array}{l}\text { "Ou seja, eu acho que isto é a melhor escola de líderes que pode } \\
\text { existir. E eu me tornei, vendo lideranças fortíssimas, e vendo as formas } \\
\text { tranquilas com que as pessoas lidam com o erro." }\end{array}$ \\
\hline $\begin{array}{l}\text { Capacidade } \\
\text { de inspirar e } \\
\text { criar uma visão } \\
\text { compartilhada }\end{array}$ & $\begin{array}{l}\text { "Visão de longo prazo, prever o futuro, interpretar um cenário, perceber } \\
\text { a importância estratégica de uma decisão para a empresa." } \\
\text { "Acho que a capacidade de você, a partir das informações que tem, } \\
\text { conseguir tomar decisões que motivem - não sei se aqui precisa motivar } \\
\text { alguém - que consiga dar norte para as pessoas agirem. De fato, não } \\
\text { acredito que exista como característica de liderança, ou o que seja a } \\
\text { liderança, a ação em si. Mas, sim, a mobilização para levar o grupo." }\end{array}$ \\
\hline Credibilidade & $\begin{array}{l}\text { "É um cara que transmite energia, que motiva, que chora junto, que ri } \\
\text { junto, que seja coerente e que não esconda as coisas. O cara não pode } \\
\text { ver no líder um cara que enganou de alguma forma, o discurso dele não } \\
\text { é bem o que ele pratica." }\end{array}$ \\
\hline Pioneirismo & $\begin{array}{l}\text { "Eu acho que para você ser líder, você tem que passar por aí também, } \\
\text { você tem que desbravar, você tem que acreditar, você tem que ser } \\
\text { pioneiro, você tem que ser vanguarda." }\end{array}$ \\
\hline Postura firme & $\begin{array}{l}\text { "E o desenvolvimento da liderança requer que você tenha coragem } \\
\text { de se posicionar, e de dizer coisas que as pessoas eventualmente não } \\
\text { querem ouvir. Ou prefeririam não ouvir." }\end{array}$ \\
\hline $\begin{array}{l}\text { Disciplina e } \\
\text { equilíbrio }\end{array}$ & $\begin{array}{l}\text { "Então, ela tem que se reconhecer enquanto líder, em uma dessas } \\
\text { categorias e buscar o seu aprimoramento individual mediante disciplina. } \\
\text { Porque, às vezes, a gente começa muito bem, mas chega uma hora que } \\
\text { aflora o seu rompante natural. Então, isso, a disciplina também é uma } \\
\text { questão que é necessária." }\end{array}$ \\
\hline
\end{tabular}

(continua) 


\section{QUADRO I (CONTINUAÇÃO)}

\section{ATRIBUTOS DE COMPETENCIAS ASSOCIADOS}

A FIGURA DO LÍDER NO CONTEXTO ATUAL

\begin{tabular}{|c|c|}
\hline $\begin{array}{l}\text { ATRIBUTOS DE } \\
\text { COMPETENCIA }\end{array}$ & RELATOS ASSOCIADOS \\
\hline Visão sistêmica & $\begin{array}{l}\text { "Então, a visão holística, ou seja, você tentar ter uma visão } 360^{\circ} \text { de } \\
\text { todas as questões, leva-o a fazer um tipo de liderança talvez mais } \\
\text { efetiva. Muitas vezes, alguns líderes nossos insistem em fazer mais } \\
\text { do mesmo, quando na verdade a gente precisa, às vezes, fazer uma } \\
\text { ruptura, fazer diferente." }\end{array}$ \\
\hline $\begin{array}{l}\text { Capacidade de } \\
\text { delegar funções }\end{array}$ & $\begin{array}{l}\text { "Uma coisa é o seguinte, no momento em que a equipe está preparada, } \\
\text { ser líder é delegar, para que as pessoas tenham o poder de decisão e } \\
\text { pratiquem isso." }\end{array}$ \\
\hline $\begin{array}{l}\text { Capacidade de } \\
\text { negociação }\end{array}$ & $\begin{array}{l}\text { "É a capacidade de buscar o entendimento. Então, ele é um negociador } \\
\text { nato e, para isso, você precisa exercitar a liderança na plenitude, } \\
\text { organizar todos esses aspectos." }\end{array}$ \\
\hline $\begin{array}{l}\text { Capacidade de } \\
\text { agregação }\end{array}$ & $\begin{array}{l}\text { "As qualidades do líder, eu diria assim, são exatamente de agregar } \\
\text { pessoas em torno de si, essa é talvez a maior." }\end{array}$ \\
\hline $\begin{array}{l}\text { Capacidade de } \\
\text { alinhar interesses }\end{array}$ & $\begin{array}{l}\text { "Ele verifica quais são os atores que estão em torno, e busca construir } \\
\text { esse objetivo, essa causa comum, de tal forma que, ao final, todos } \\
\text { concordem de que aquela solução é a melhor que foi apresentada até o } \\
\text { momento." }\end{array}$ \\
\hline $\begin{array}{l}\text { Capacidade de } \\
\text { assumir riscos }\end{array}$ & $\begin{array}{l}\text { "É muito importante que o líder não tenha medo de tomar risco. Ele } \\
\text { compartilha a decisão, ele escuta a decisão, mas ele não tem medo de } \\
\text { tomar risco. E cada vez mais essa função, essa palavra, esse aspecto de } \\
\text { liderança, é cobrada do líder essa responsabilidade de tomar risco." }\end{array}$ \\
\hline $\begin{array}{l}\text { Otimismo e bom } \\
\text { humor }\end{array}$ & $\begin{array}{l}\text { "Bom, outra coisa que eu vejo na liderança, que é fundamental, é ter } \\
\text { alegria. É contagiar as pessoas. É, de trazer uma energia positiva para } \\
\text { dentro. Porque, por mais que você reconheça, se você está com aquela } \\
\text { carga pesada, você contagia muito as pessoas. Um ambiente mais leve é } \\
\text { muito mais fácil de trabalhar do que um ambiente mais contaminado." }\end{array}$ \\
\hline $\begin{array}{l}\text { Capacidade de } \\
\text { mobilização }\end{array}$ & $\begin{array}{l}\text { "Mas eu gosto de dar aos meus supervisores, técnicos e tudo, liberdade } \\
\text { para fazer a sua gestão de área. Eu faço muito pouca ingerência e } \\
\text { controlo os resultados. Do contrário acaba tirando a criatividade das } \\
\text { pessoas, as pessoas acabam ficando muito restritas na forma da sua } \\
\text { criatividade." }\end{array}$ \\
\hline
\end{tabular}

(continua) 


\section{QUADRO I (CONCLUSÃO)}

ATRIBUTOS DE COMPETENCIAS ASSOCIADOS

A FIGURA DO LÍDER NO CONTEXTO ATUAL

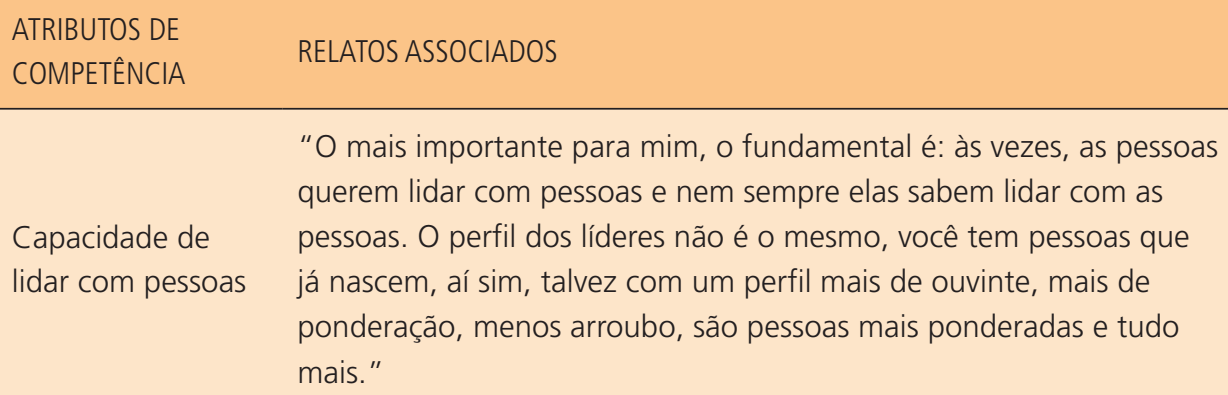

Fonte: Elaborado pelos autores.

Vale ressaltar que tais atributos resultam de menções de pessoas que possuem perspectivas diferentes sobre características do "líder eficaz". Não se observando, todavia, consenso acerca do que constitui a liderança, em si. Observam-se, de qualquer modo, similaridades e/ou complementaridades em vários dos atributos relatados pelos diferentes respondentes. Ao final, tais atributos puderam ser agrupados em quatro conjuntos, que representam estilos de liderança, bem aos moldes dos preconizados por Blake e Mouton (I964) e Kouzes e Posner (I997), e sintetizados no Quadro 2.

\section{QUADRO 2}

PRINCIPAIS ESTILOS DE LIDERANÇA SEGUNDO OS EXECUTIVOS PESQUISADOS

\begin{tabular}{ll}
\hline ESTILO DE LIDERANÇA & PRINCIPAIS ATRIBUTOS DE LIDERANÇA \\
\hline $\begin{array}{l}\text { Líder orientado para } \\
\text { pessoas }\end{array}$ & Saber lidar com pessoas, saber lidar com o erro, ser agregador. \\
\hline Líder visionário & $\begin{array}{l}\text { Ter visão holística e de longo prazo, ser pioneiro, ter curiosidade, } \\
\text { ser mobilizador. }\end{array}$ \\
\hline Líder mobilizador & $\begin{array}{l}\text { Saber alinhar interesses, ser mobilizador, ter boa capacidade de } \\
\text { negociação. }\end{array}$ \\
\hline Líder ambivalente & $\begin{array}{l}\text { Manter disciplina e equilíbrio, ter postura firme, } \\
\text { saber lidar com pessoas, ter boa capacidade de negociação. }\end{array}$ \\
\hline
\end{tabular}

Fonte: Elaborado pelos autores. 
Pelo Quadro 2, as categorias dispostas na coluna da esquerda representam os principais comportamentos pelos quais os líderes se apresentam e consideram ser percebidos por seus liderados. Já a coluna da direita apresenta os atributos mais comumente associados aos estilos de liderança relatados. Deve-se ressaltar, no entanto, que os atributos de liderança indicados não podem ser definidos como exclusivos de um único estilo de liderança. Em outros termos, um "líder mobilizador" pode ser reconhecido por sua "postura firme", ou um "visionário" apresentar "boa capacidade de negociação".

De qualquer forma, o líder orientado para pessoas é aquele que se concentra no relacionamento com liderados, praticando o diálogo e dando feedback constante. A interação entre ambos é baseada na confiança. Além da predisposição para tratar com pessoas, esse tipo de líder entende que todos são passíveis ao erro.

Ele tem que ter tempo para ouvir as pessoas. E quando eu digo ouvir as pessoas, é tempo mesmo, é dedicar um tempo. Não é fazer uma conversa de dez minutos e achar que ouviu alguém. É dar atenção. Um passo além. Dar feedback, um líder tem que fazer isso.

$\mathrm{Eu}$ tento fazer isto com as pessoas que trabalham comigo. Significa escutar, orientar, ajudar, ajudar também, não só no trabalho, mas também quando as pessoas precisam de ajuda.

O estilo de liderança visionário, por sua vez, analisa diferentes perspectivas e tendências do ambiente interno e externo da organização para desenvolver uma visão clara de onde se quer chegar. Essa visão orienta as ações dos liderados, mas como ela tende a antever tendências que rompem com o status quo prevalecente, ele precisa motivá-los e ter boa aptidão em convencimento. Em muitos casos, a formação dessa visão depende do pioneirismo e curiosidade do líder.

E no caso, é a chamada disruptura mesmo, então você deixa o que é antigo para trás e faz um, começa um novo.

Vimos mais ou menos fazendo um percurso juntos desde i995, e o que me impressionou nele é a visão que ele teve. A maior expressão da liderança dele é na visão.

Já o estilo de liderança mobilizador é reconhecido por levar liderados com diferentes interesses a compartilhar objetivos comuns. Seu desempenho inspira as pessoas a agir, é orientado para a ação. Ele visualiza na negociação o meio de cativar as pessoas na busca por resultados. Depende, portanto, de sua grande capacidade de convencimento. 
Ele é sedutor. Eu acredito na força das palavras. Ele acredita mais no jeito de se pronunciar.

Cada vez mais mobilizador e ser mobilizador sem, digamos, sem a chave da porta da hierarquia.

O líder é o que consegue fazer a mágica e deixar, pelo menos, todas as partes satisfeitas alcançando o projeto para o qual ele foi colocado como líder.

Finalmente, o líder ambivalente concilia a orientação para pessoas com a busca por resultados. Isso exige que tenha disciplina e equilíbrio para utilizar sua boa capacidade de relacionamento em prol da negociação e avaliação de desempenho com os liderados. Esse processo exige, em muitos casos, que o líder adote uma postura firme.

É buscar resultado, é sentar na reunião de negociação e ser duro o quanto for necessário, mas nunca esquecer que tem que ter um lado gentil também, que é você aprender a lidar com as pessoas, ter certo grau de suavidade com as pessoas e com você mesmo. Você precisa conseguir equilibrar essa balança, ser o forte e o gentil. E a gente busca isso com afinco.

As quatro posturas de liderança que emergiram da análise das entrevistas demonstram a importância de novos atributos de liderança. Afinal, o líder "deve se modificar conforme evoluem as demandas das organizações e orientação das pessoas". Algumas dessas demandas, no entanto, também lhes impõem novos desafios, conforme os destacados no Quadro 3.

\section{QUADRO 3}

\section{DESAFIOS E ATRIBUIÇÕES DO LÍDER NA CONTEMPORANEIDADE}

DESAFIOS EVIDÊNCIAS

"Cada executivo tem que flexibilizar o modus operandi onde ele vá realizar este valor por cada país [...] Não adianta tentar mudar a cultura do país porque é bater com a cara na porta. O que eu preciso é formar líderes,

Desenvolver que sabem quais são os valores, e que saiba trilhar este caminho com toda líderes capazes realidade cultural onde que a empresa opera naquele momento."

de lidar com a "Aí, tem outra coisa do líder, eu acho. O líder não é aquele que coloca multiculturalidade todo mundo igual. Ele tem que colocar pessoas diferentes para trabalhar com ele e saber ouvi-las. Eu falo isso para todos os gerentes nossos. Não adianta você formar um clone e deixa que a gente faz com árvore, que é o nosso negócio." 
QUADRO 3 (CONCLUSÃo)

DESAFIOS E ATRIBUIÇÖES DO LÍDER NA CONTEMPORANEIDADE

\begin{tabular}{|c|c|}
\hline DESAFIOS & EVIDÊNCIAS \\
\hline $\begin{array}{l}\text { Desenvolver } \\
\text { líderes capazes } \\
\text { de lidar com a } \\
\text { multiculturalidade }\end{array}$ & $\begin{array}{l}\text { "É porque a sociedade é um plural de indivíduos, assim como as } \\
\text { organizações são um plural de esforços de indivíduos que ali estão para } \\
\text { compor esses objetivos." }\end{array}$ \\
\hline $\begin{array}{l}\text { Formar e } \\
\text { desenvolver } \\
\text { equipes } \\
\text { com elevada } \\
\text { diversidade }\end{array}$ & $\begin{array}{l}\text { "Então, o grande desafio de um líder é ter uma equipe com pessoas } \\
\text { novas, porque você nunca vai ter uma equipe formada a vida inteira, } \\
\text { você perde as pessoas com o tempo, e é natural. Daqui a pouco já } \\
\text { vamos falar de um outro grupo de pessoas. Então, você perde, ganha, } \\
\text { então, tem que ter um grupo de pessoas muito bem preparadas, } \\
\text { maduras, um grupo de pessoas novas, que estão entrando, que você } \\
\text { tem que fazer aprender e uns } 70 \% \text { no auge de capacidade. E esse } \\
\text { conjunto é que tem que ser um conjunto vencedor." } \\
\text { "Acredito sinceramente que, cada vez menos, o papel do gestor em } \\
\text { si vai ser tão importante dentro da empresa. Porque cada vez mais as } \\
\text { pessoas estão trabalhando em equipe, em células interdependentes [...] } \\
\text { Então de repente, vai ter que ser muito mais valorizado, mais valorizado } \\
\text { do que hoje dentro da equipe, dentro das empresas, aquela pessoa que } \\
\text { tem o perfil de liderar grupos distintos por objetivos pontuais." }\end{array}$ \\
\hline $\begin{array}{l}\text { Desenvolver } \\
\text { redes de } \\
\text { relacionamentos }\end{array}$ & $\begin{array}{l}\text { "É, e a outra coisa é ter uma visão da rede, quer seja interna, na empresa; } \\
\text { quer seja externa, as redes estratégicas e as redes que fazem as coisas } \\
\text { acontecerem. Então ter uma dimensão dessa rede, de montar essa rede } \\
\text { estratégica, o que é importante nessa rede estratégica, investir tempo } \\
\text { nisso, desenvolver essa rede estratégica. Porque ela vai dar dimensão de } \\
\text { sustentabilidade para a sua empresa, internamente e externamente." }\end{array}$ \\
\hline $\begin{array}{l}\text { Liderar em } \\
\text { ambientes } \\
\text { dinâmicos }\end{array}$ & $\begin{array}{l}\text { "Acredito que tem que ser um líder que pense muito rápido, que ele vai } \\
\text { ter pouco tempo, cada vez menos tempo para tomar decisões. Então, } \\
\text { ele vai ter que pensar rápido e estar confortável de tomar as decisões } \\
\text { com menos informações. Vai ter que ser um líder que tenha uma leitura } \\
\text { muito precisa das pessoas. As pessoas vão emitir, como sempre emitiram, } \\
\text { alguns sinais, e esse líder vai ter que, rapidamente, captar esses sinais e } \\
\text { entender qual é a melhor maneira de lidar com aquilo." }\end{array}$ \\
\hline
\end{tabular}

Fonte: Elaborado pelos autores.

A partir do conjunto dos dados disponibilizados no Quadro 3, destaca-se a relevância de preparar lideranças para a atuação em diferentes contextos geográ- 
ficos e culturais, com capacidade de conviver e assimilar valores e culturas distintos. Tal demanda, associada ao caráter altamente dinâmico do mundo atual, requer, por conseguinte, atributos como sensibilidade para tomada de decisões rápidas, porém baseadas em "sinais" emitidos pelo ambiente e pelos liderados. Demanda, igualmente, "líderes mais próximos", isto é, que tenham habilidade de se relacionar com as pessoas, construindo múltiplas redes de relacionamento.

A capacidade de trabalho em equipes e projetos representa outra competência bastante enfatizada ao longo dos relatos obtidos. Nesse sentido, merece destaque a consideração de que o líder deve ter "a incumbência de garantir a complementaridade de competências e diversidade das características dos membros de suas equipes". Mais que isso, deve mostrar-se apto a liderar inúmeros "times de liderados", compostos para os mais variados fins e com os mais diversos perfis profissionais.

\subsection{DESENVOLVIMENTO DE LIDERANÇAS}

Outro tema abordado pelos executivos entrevistados refere-se a valores, experiências e relacionamentos capazes de influenciar o processo de desenvolvimento de lideranças.

Ainda que muitas características do líder sejam apontadas como inatas, alguns dos entrevistados assinalam a contribuição das primeiras experiências no ambiente sociofamiliar como fundamentais ao processo de formação do líder. Nessa direção, a figura dos pais, professores e familiares próximos funcionou como suporte para identificação ou modelos estruturadores do imaginário da liderança:

Então partiu da minha família que também tem aquela mineirice. E, às vezes, eu acho que a mineirice atrapalha um pouco esta coisa. O mineiro tem um traço de humildade, que é positivo por um lado, mas às vezes fica tacanho, fica um pouco "medíocre". Então a gente vê grandes líderes mineiros, mas a sociedade mineira, ela não apoia as lideranças fortes, ela quer a mediana. Ela força muito, ela empurra muito as pessoas para um padrão médio de conduta.

Então evidentemente o meu pai sempre foi um líder muito forte, filho mais velho de pai militar, e então ele replicou aquela conduta do pai dele. E muito carismático no relacionamento pessoal. Então é aquela figura simbólica muito presente e muito forte [...]. Com aquela idolatria toda eu fui, então, forjando uma dada visão de liderança.

No entanto, quando abordados sobre suas trajetórias profissionais, diversos respondentes salientam a relevância de suas carreiras como base para o desenvolvimento da liderança. 
Constata-se, por exemplo, que nem todas as características de liderança inatas e/ou adquiridas mostraram-se aderentes às primeiras experiências de trabalho, para eles, momentos importantes de desconstrução e ressignificação de valores e conhecimentos. Em tais processos, as principais referências são as figuras de superiores imediatos, diretores ou presidentes de empresas de sucesso ou a que se vincularam pessoalmente ou mesmo pessoas públicas, tais como líderes governamentais:

Depois eu tive pessoas dentro das próprias empresas que eu passei a ter como inspiração. Eu tive dois chefes maravilhosos. Um era o diretor florestal, que me deixou como sucessor, e com ele eu aprendi exatamente isso: como fazer sucessão. Um outro, um espanhol, foi um presidente, um senhor com quem eu conversava a cada 40 dias. Ele delegava todas as responsabilidades para mim, mas sabia me apoiar. Eu aprendi isso com ele.

E isso é interessante, porque eu sou advogado em empresas que sempre eram dominadas pelos engenheiros. Então talvez, isso foi uma mistura, um blend bem interessante, porque eu aprendi a entender cartesiano, mas conversando de uma forma menos cartesiana. Então eu consegui entender até que ponto ser cartesiano era importante para me alavancar e conseguia misturar algumas coisas que o cartesiano não conseguia enxergar. Isso foi muito bom.

O meu exemplo de um líder que eu conheci é de um líder nato, é um homem pronto e acabado, pronto para uma função até maior do que a que ocupa. Ele é uma liderança em que a gente se inspira bastante. Pelo comedimento, pela praticidade e principalmente pela forma como ele consegue orquestrar uma série de entendimentos, ele é um agregador de equipes.

Interessante notar, pelos depoimentos obtidos, que as experiências mais marcantes se deram em momentos de dificuldades e frustrações. Tais circunstâncias envolveram incertezas quanto a, por exemplo, resultados de processos de seleção para funções mais desafiadoras, exposição ao risco, dificuldades no relacionamento com superiores, atuação em novos ambientes e incapacidade de contribuições para um maior desempenho da empresa:

Não, o líder é forjado mais no fracasso que na vitória. A gente tem que apanhar muito para, no momento seguinte, saber como lidar com as situações. Então a experiência é algo fundamental.

E eu tinha que escolher o meu diretor de planejamento e desenvolvimento de pessoas e colocá-los em casa para preparar e planejar uma operação na Líbia, e isto para mim foi uma experiência que por vários momentos eu pensava assim: "Será que eu estou com as pessoas certas? Será que eles vão dar conta do recado?". 
Soma-se a isso a compreensão pelos executivos pesquisados que o desenvolvimento de competências em liderança é um processo contínuo, em que se lida permanentemente com novos gaps e barreiras a serem superados. A prioridade dada às atividades rotineiras (gerenciais), por exemplo, é apontada como obstáculo à construção de uma ambiência organizacional em que se favoreçam o desenvolvimento e a aplicação de atributos de competências mais afins ao exercício e desenvolvimento da liderança. Outro obstáculo é a dificuldade de tempo para ações de aprendizagem contínua e para participação em programas e atividades que estimulem o desenvolvimento de novos atributos de liderança. Além disso, registra-se a demanda por atributos de liderança ainda pouco consolidados.

Eu acho que cada pessoa tem qualquer ponto fraco, eu gostaria de ter maior conhecimento, conhecimento técnico. Porque não entendo técnico de engenharia e escritório, mas eu falo de cultura própria.

Então eu gostaria de ter mais tempo para investir no novo, sabe? Tecnologia nova, trazer, de fazer mais isso. Quando falo que eu sou ligado ao fato de que eu não consigo administrar sem saber o que o concorrente está fazendo, muitas vezes vai a equipe e eu queria eu mesmo estar lá, sabe? Queria eu mesmo estar indo lá.

\subsection{LIDERANÇA E CONTEXTO CAPACITANTE}

Além da análise da liderança sob a perspectiva da pessoa do líder e de sua relação com seus times de liderados, os executivos também analisaram o tema sob o prisma organizacional, em referência à cultura e ao ambiente interno das organizações, e suas implicações sobre o desenvolvimento da liderança. Igualmente, foram abordadas políticas e práticas de gestão capazes de estimular a construção de contextos capacitantes mais afins à noção contemporânea de liderança.

Nessa direção, merece destaque a importância atribuída à disseminação da estratégia e da visão de negócios da empresa. Diversos relatos indicam tal fator como elemento fundamental do processo de liderança, na medida em que, por meio dele, as pessoas se sentem mais motivadas, atribuindo maior sentido ao seu trabalho e papel na organização. Para eles, uma atribuição central da liderança contemporânea é garantir a inclusão das pessoas nos processos de formulação estratégica, com estímulos a uma gestão efetivamente participativa.

68 Tal prática, inclusive, contribui para o fomento à construção de uma cultura organizacional que favoreça o pensamento estratégico, o compartilhamento de informações, conhecimentos e valores, fundamentais aos processos de renovação e transformações continuamente requeridos às organizações atuais, como fruto do atual contexto dos negócios, relatam. 
Concomitantemente, tal processo é apontado como elemento importante ao desenvolvimento de líderes ao propiciar maior engajamento e autonomia para aproveitar oportunidades dos ambientes interno e externo:

Agora, isso só é possível se você tem essa liderança coletiva consolidada na cabeça de cada um. Ninguém aqui ficou com medo.

Tem empresa que tem orientação, tem estratégia. Então eu acho que, primeiramente, é importante que o líder se inteire do pipeline da empresa, significa que pega no seu corpo, na cabeça com toda a estratégia da empresa e traz em mente junto com esta estratégia as pessoas que trabalham junto com ele. E significa também que as pessoas que trabalham com o líder aceitam a decisão do líder, porque entendem que esta decisão é uma decisão certa, para ele, para o colaborador ou colega, e logicamente pela empresa também.

Outro aspecto evidenciado pelos respondentes diz respeito à coerência do relacionamento da organização com seus diferentes stakeholders. Para alguns dos entrevistados, não basta concatenar esforços internos que orientem a ação e desenvolvimento de líderes, é necessário, além disso, inspirar esses indivíduos a levar em conta clientes, parceiros e fornecedores. Dessa forma, maior ênfase se estabelece ao papel da liderança, como elemento que extrapola os limites da organização e de seus negócios, incorporando uma visão externa que garanta a legitimidade de suas ações e a sustentabilidade de seus negócios em si, em longo prazo.

Vale ressaltar, entretanto, que tal compromisso com a dimensão social e de sustentabilidade, em longo prazo, não ignora a dimensão do desempenho imediato da organização: nota-se, pelos relatos analisados, significativa associação entre cumprimento de metas e objetivos à imagem do líder bem-sucedido.

Mas você tem que saber liderar quem não é da sua equipe também, você tem que saber liderar o seu cliente, você tem que saber liderar os seus parceiros. Então você empurra a pessoa, a gente se empurra numa direção correta. A gente se empurra numa direção de como conduzir os processos, como liderar, como focar, como priorizar, como rever estratégia.

Então o objetivo maior da liderança é transformar a organização em uma organização líder, e transformar essa organização líder em uma líder sustentável ao longo do tempo. Para isso, ele precisa instituir políticas, precisa instituir visões e, mais do que isso, ele precisa instituir nas organizações, a ideia de compromisso. Compromisso com o resultado é um dos pontos, tem outros compromissos que precisam vir junto: compromisso com as pessoas e o compromisso com a sociedade. Senão, a organização em si, vai achar que ela se basta. 
É nesse ambiente, repleto de contradições e ambiguidades, que se visa forjar as condições para atração e retenção das novas gerações de líderes, pretensamente, mais preocupadas com a questão da sustentabilidade e de maior atribuição de sentido à suas vidas, bem como ao seu trabalho. Consequentemente, há que se mencionar os desafios e preocupações quanto a como lidar com as novas gerações, em particular com a chamada Geração Y, que, em breve, deverá assumir posições-chave nas organizações, em decorrência da aposentadoria dos Baby Boomers.

E as características que eu vejo, em um ambiente desse tipo, é um ambiente que consiga atrair as pessoas dispostas a se identificar com outras dentro da organização. E essa coisa funciona como uma bola de neve. Eu consigo ter uma pessoa que cria identidade. Essa pessoa traz dois, três que vão se espelhar nele, desenvolver características próprias a partir daquele ambiente, que vão atrair outros e, daqui a pouco, está todo mundo comentando que aquele ambiente é um ambiente bom para se desenvolver liderança, e é uma empresa, que fez um ambiente qualquer, que exporta líderes.

Ele acaba sendo um ímã, um ímã no geral, no mercado. E aí, eu passo a criar, a partir da atração eu começo a criar essa ambiência favorável ao desenvolvimento de liderança. Esse é o passo, o passo que talvez demande menos energia.

Na perspectiva de grande parte dos entrevistados, tal atração e retenção de novos líderes passarão pela reestruturação das áreas de pessoas das empresas, com maior ênfase em práticas baseadas, por exemplo, na avaliação de desempenho e na gestão participativa.

Então, a gente deu o passo nesse sentido também, que é conseguir colocar nas áreas de recursos humanos pessoas que acreditem no desenvolvimento de pessoas e que consigam dar esse ferramental para todas as pessoas que nós queremos desenvolver. Uma coisa é dar ferramental e a outra coisa é você ir peneirando esse grupo, para identificar: Puxa, esse é líder. Puxa, esse é líder, esse é líder, esse é líder. Esse daqui não é líder, desloca para outro tipo de atividade. Esse é líder, vamos colocar na berlinda. Então a gente está caminhando com essas três, quatro coisas ao mesmo tempo.

Depois, vem um outro processo, que eu acho que é muito bom na formação do líder que aí já é um pouco mais prático, que é agenda, a gente chama de programa de ação aqui. É o balanced scorecard que você tem que ter de uma forma muito pragmática e muito dentro do dia a dia. Então você forma uma cadeia quando você consegue implementar essa metodologia empresarial, quando você consegue 
praticar isto aí, aí você está, ao mesmo tempo, fazendo uma escola de líderes, uma escola de empresários como a gente chama aqui. Quando você atinge os objetivos que sejam pragmáticos, você está atingido um objetivo intangível que é a formação de uma pessoa conceitual, pragmática, focada em concentrações específicas, estrategista, reflete-se sobre estas estratégias.

Delineado o panorama dos principais temas, questões e desafios que caracterizam a agenda de preocupações estratégicas dos executivos pesquisados em relação à temática da liderança, apresenta-se, no tópico a seguir, uma síntese dos resultados e conclusões.

\section{CONSIDERAÇÕES FINAIS}

A partir do conjunto dos relatos dos executivos brasileiros pesquisados, foi possível agrupar as principais questões e desafios em torno da liderança, em três dimensões-chave: Sentidos, competências, Estilos e Desafios associados à Liderança no Contemporâneo; Desenvolvimento de Lideranças; Liderança e Contexto Capacitante. Tais achados permitem constatar certa aderência entre as preocupações estratégicas relatadas pelos respondentes e as principais questões e desafios à liderança e seu desenvolvimento, conforme preconizados pela literatura mais contemporânea sobre o tema. Um deles é o caráter polissêmico e contingente desse construto, o qual compreende múltiplas definições e abordagens, que se modificam conforme as alterações no contexto. Outro corresponde à importância e aos desafios atribuídos à instância do desenvolvimento de lideranças, incluindo a construção de ambiências organizacionais que favoreçam a atração e retenção de líderes com a amplitude de atributos individuais requeridos pelo atual contexto dos negócios e das organizações.

Merece destaque, inclusive, a relação de características, apontadas pelos executivos entrevistados, como esperadas de um líder nesse atual contexto: capacidade de assumir responsabilidades; curiosidade; capacidade de lidar com o erro; capacidade de inspirar e criar uma visão compartilhada; credibilidade; pioneirismo; postura firme; disciplina e equilíbrio; visão sistêmica; capacidade de delegar funções; capacidade de negociação; capacidade de agregação; capacidade de alinhar interesses; capacidade de assumir riscos; otimismo e bom humor; capacidade de mobilização; capacidade de lidar com pessoas. Tal achado não deixa de remeter à síndrome de construção de um super-homem identificada por Gitahy e Fischer (I996), em pesquisa realizada em subsidiária de corporação multinacional que opera no país, assim como estudo conduzido por Luz (200I), com a grande empresa nacional do setor de telecomunicações. 
Esse amplo conjunto de atributos, ao final, pôde, todavia, ser agrupado em quatro conjuntos, que representam os seguintes estilos de liderança: Líder orientado para pessoas; Líder visionário; Líder mobilizador e Líder ambivalente, em conformidade àqueles relatados por Blake e Mouton (I964) e por Kouzes e Posner (I997).

Como desafios à liderança no atual contexto, os respondentes destacam aspectos tais como: desenvolver líderes capazes de lidar com diversidade cultural; formar e desenvolver equipes com elevada diversidade; desenvolver redes de relacionamentos e liderar em ambientes dinâmicos. Outro desafio diz respeito aos valores, às experiências e aos relacionamentos que o líder deve construir, vivenciar e compartilhar, de modo a influenciar positivamente o processo de desenvolvimento de lideranças. Nessa direção, para além da ampla disseminação da liderança transformacional, é sintomático o crescente interesse por abordagens que enfatizam aspectos multidimensionais e multiníveis, capazes de capturar, de forma mais sistêmica, inter-relações entre variáveis múltiplas, que marcam a dinamicidade e complexidade dos atuais ambientes organizacionais e de negócios, como a abordagem proposta por Yammarino, Dansereau e Kennedy (200I).

Além disso, os achados apontam a relevância de abordagens que consideram, de forma mais sistemática, como a chamada Teoria LMX, relações entre líderes e seus liderados. Adicionalmente à análise da liderança sob a perspectiva da pessoa do líder e de sua relação com seus times de liderados, destaca-se, também, a ênfase atribuída à relevância da cultura e da construção de contextos capacitantes que permitam sustentar os processos de atração, desenvolvimento, assim como promover a retenção de lideranças, em particular, de futuras lideranças. Quanto a esse aspecto, foi possível constatar a preocupação quanto a como lidar com as novas gerações, em especial com a chamada Geração Y, que, em breve, deverá assumir posições-chave nas organizações, em decorrência de fatores demográficos, dentre eles a aposentadoria dos Baby Boomers. A questão geracional, evidenciada aqui como exemplo de desafio à liderança em contextos de maior complexidade e diversidade de variáveis intervenientes - ou melhor, de diversidades (no plural): geracional, cultural, geográfica, de stakeholders - requerendo revisitas sistemáticas a outros elementos do comportamento organizacional - motivação, comprometimento, valores, comunicação - quanto às suas relações com a liderança, em particular, considerando o domínio cada vez mais amplo das noções de gestão e de business (GAULEJAC, 2007).

Em suma, os achados permitem, a partir da perspectiva de atores diretamente envolvidos na problemática da liderança, no contexto empresarial, subsídios ao aprofundamento do debate, assim como à formulação de novas agendas e linhas de pesquisas sobre o tema. 


\section{LEADERSHIP FROM THE PERSPECTIVE OF BRAZILIAN EXECUTIVES}

\section{ABSTRACT}

This article aims to present results of a study designed to investigate major issues and challenges related to the theme of leadership and its development, in the contemporary world, from the perspective of senior executives of large Brazilian companies. With respect to this purpose, its specific objectives may be described as: I. to investigate both assigned meanings and leadership styles connected to experience and practice of the interviewed executives; 2 . to investigate key themes to leadership development in the current context of businesses and organizations; 3 . to identify present-day tendencies, new themes and challenges surrounding leadership. As a theoretical framework, a literature review was conducted to describe the evolution of studies on the subject, especially its major theoretical, methodological and conceptual trends and approaches. In methodological terms, the research underlying the results may be characterized as qualitative in nature and descriptive in character, its primary data being derived from semi-structured, in-depth interviews carried out with thirteen senior executives of large national and international corporations operating in the states of São Paulo and Minas Gerais (Brazil). Data were subsequently treated with the help of NVivo 8 software application and the major leadership-related themes and challenges identified were grouped into three key themes: Meanings, Competencies and Styles associated with Leadership in the Contemporary World, Development of Leaderships, Leadership and Enabling Context. The study has also allowed identification of the major competence and leadership style attributes required to respond to the current context of businesses and organizations, according to the interviewees' viewpoint. Concurrently, new challenges and concerns related to leadership were also disclosed, such as how to deal with new generations especially the so-called Y-Generation -, who will soon be holding key positions in organizations, following retirement of the baby boomers. In brief, from the standpoint of players involved with leadership in business contexts, the finds enabled the emergence of questions and challenges to be included in new agendas or addressed by new research lines on the subject.

\section{KEYMORDS}

Leadership; Leadership Development; Development of Executives; Leadership Styles; Leadership Competencies. 


\section{LIDERAZGO: ¿QUÉ PIENSAN LOS EJECUTIVOS BRASILEÑOS SOBRE EL TEMA?}

\section{RESUMEN}

Este artículo tiene como objetivo presentar resultados de estudio realizado con el intuito de investigar las principales cuestiones y desafíos en torno de la temática del liderazgo y su desarrollo, en la contemporaneidad, desde la perspectiva de altos ejecutivos de grandes empresas brasileñas. Considerando tal propósito, los objetivos específicos son: I. Investigar sentidos atribuidos y estilos de liderazgo articulados a la vivencia y práctica de los ejecutivos investigados; 2 . Investigar temas clave al desarrollo de liderazgos en el actual contexto de los negocios y de las organizaciones; 3. Identificar tendencias, nuevos temas y desafíos en torno de la temática del liderazgo, en lo contemporáneo. Como referente teórico, cabe resaltar la revisión de literatura involucrando descripción evolutiva de los estudios sobre la temática, con destaque para sus principales corrientes y enfoques teórico-metodológico-conceptuales. En términos metodológicos, la investigación que subsidió los resultados de este estudio se la puede caracterizar como de naturaleza cualitativa y carácter descriptivo, teniendo sus datos primarios derivados de entrevistas semiestructuradas y, en profundidad, realizadas junto a trece altos ejecutivos de grandes corporaciones, nacionales e internacionales, ubicadas en São Paulo y Minas Gerais. Tras el tratamiento de los datos, con el auxilio del software de tratamiento cualitativo NVivo 8, fue posible agrupar los principales temas y desafíos identificados en torno del liderazgo en tres temas clave: Sentidos, Competencias, Estilos y Desafíos asociados al Liderazgo en lo Contemporáneo; Desarrollo de Liderazgos; Liderazgo y Contexto Capacitador. El estudio posibilitó, también, identificar los principales atributos de competencia y estilos de liderazgo requeridos como respuesta al actual contexto de los negocios y organizaciones, según la perspectiva de los ejecutivos entrevistados. Concomitantemente, fue posible constatar nuevos desafíos y preocupaciones con relación a la temática del liderazgo como, por ejemplo, cómo actuar con las nuevas generaciones que pronto deberán asumir posiciones clave en las organizaciones. En resumen, los resultados permiten, desde la perspectiva de los propios actores directamente implicados en la problemática del liderazgo en el contexto empresarial, la emergencia de cuestiones y desafíos a ser contemplados en nuevas agendas de desarrollo y líneas de investigación sobre el tema.

\section{palabras CLAVE}

Liderazgo; Desarrollo de Liderazgo; Desarrollo de Ejecutivos; Estilos de Liderazgo; Competencias en Liderazgo. 


\section{REFERÊNCIAS}

BADARACO, J.; ELLSWORTH, R. Leadership and quest for integrity. Boston: Harvard Business School Press, I989.

BASS, B. M. Handbook of leadership: survey of theory and research. New York: The Free Press, I990. BASS, B. M.; AVOLIO, B. J. The implications of transactional and transformational leadership for individual, team and organizational development. Research in Organizational Change and Development, v. 4, p. 23I-272, I990.

BENNIS, W.; NANUS, B. Líderes: estratégias para assumir a verdadeira liderança. São Paulo: Harbra, I985.

BERGAMINI, C. W. Liderança: administração do sentido. São Paulo: Atlas, I994.

BLAKE, R.; MOUTON, J. The managerial grid. Houston: Gulf Publishing, I964.

BURNS, J. M. Leadership. New York: Harper \& Row, 1978.

BURNS, T.; STALKER, G. M. The management of innovation. London: Tavistock Publications, I96I. CARLYLE, T. On heroes, hero-worhip and the heroic in history. Berkeley: University of California Press, I842.

DANSEREAU, F.; GRAEN, G.; HAGA, W. J. A vertical dyad linkage approach to leadership in formal organizations, Organizational Behavior and Human Performance, v. I3, p. 46-78, I975.

FIEDLER, F. E. A theory of leadership effectiveness. New York: McGraw-Hill, I967.

FISCHER, T. Gestão do desenvolvimento e poderes locais: marcos teóricos e avaliação. Salvador: Casa da Qualidade, 2002.

FLICK, U. Introdução à pesquisa qualitativa. Porto Alegre: Artmed, 2009.

GAULEJAC, V. Gestão como doença social: ideologia, poder gerencialista e fragmentação social. Aparecida: Ideias \& Letras, 2007.

GRAEFF, C. The situational leadership theory: a critical review. Academy of Management Journal, v. 8, p. 285-29I, I983.

GIOIA, D. A.; THOMAS, J. B. Identity, image and issue interpretation: sensemaking during strategic change in academia, Administrative Science Quarterly, v. 4I, p. 370-403, I996.

GITHAY, L.; FISCHER, R. M. Produzindo a flexibilidade: algumas reflexões sobre as aventuras e desventuras da gerência pós-moderna. In: CONGRESSO LATINO AMERICANO DE SOCIOLOGIA DO TRABALHO. Comunicações apresentadas... São Paulo: Alast, I996.

HERSEY, P.; BLANCHARD, K. H. Management of organizational behavior. Englewood Cliffs: Prentice Hall, ig69.

HIGGS, M. How can we make sense of leadership in the 2Ist century. Leadership \& Organization Development Journal, v. 24, Issue 5/6, p. 73, 2003.

HORNER, M. Leadership theory: past, present and future. Team Performance Management, v. 3, n. 4, p. 270-287, I997.

HOUSE, R. J. A path goal theory of leader effectiveness. Administrative Science Quarterly, v. I6, n. 3, p. 32I, set. I97I.

HOUSE, R. J.; MITCHELL, T. R. Path-goal theory of leadership. Contemporary business, n. 3, p. 8I-98, I974.

JUDGE, T. A.; BONO, J. E. Five-factor model of personality and transformational leadership. Journal of Applied Psychology, v. 85, Issue 5, p. 751-765, Oct. 2000. 
KOUZES, J. M.; POSNER, B. O desafio da liderança. Rio de Janeiro: Campus, I997.

LIKERT, R. New patterns of management. New York: McGraw-Hill, I96I.

LUZ, T. R. Telemar-Minas: competências que marcam a diferença. 200I. Tese (Doutorado em Administração)-Universidade Federal de Minas Gerais, Belo Horizonte, 200I.

MCGREGOR, D. Leadership and motivation. Cambridge: MIT Press, I966.

MILES, M. B.; HUBERMAN, A. M. Qualitative data analysis. Cambridge: Cambridge University Press, I994.

NANUS, B. Visionary Leadership: creating a compelling sense of direction for your organization. San Francisco: Jossey-Bass Publishers, I992.

NORTHOUSE, P. G. Leadership: theory and practice. Thousand Oaks: Sage, 2004.

PICCOLO, R. F.; COLQUITT, J. A. The effect of transformational leadership on employees job satisfaction and organizational commitment: mediating role of job characteristics. Academy of Management Journal, v. 49, n. 2, p. 327-340, 2006.

ROBBINS, S. P. Comportamento organizacional. São Paulo: Prentice Hall, 2002.

SCHEIN, E. Organizational culture and leadership. New York: Jossey \& Bass, I992.

SETERS, D. A.; FIELD, R. H. G. Leadership. Journal of Organizational Change Management, v. 3, Issue 3, p. 29, I990.

SMITH, B. N.; MONTAGNO, R. V.; KUZMENKO, T. N. Transformational and servant leadership: Content and contextual comparisons. Journal of Leadership and Organizational Studies, v. Io, n. 4, p. 80-91, 2004 .

STOGDILL, R. M. Leadership, membership and organization. Psychological Bulletin, v. 47, p. I-I4, I950. STOGDILL, R. M. Handbook of leadership. New York: MacMillan, Free Press, I974.

VROOM, V. H.; YETTON, P. W. Leadership and decision-making. Pittsburgh: University of Pittsburgh Press, I973.

YAMMARINO, F. J.; DANSEREAU, F.; KENNEDY, C. J. A multiple-level multidimensional approach to leadership: viewing leadership through an elephant's eye. Organizational Dynamics, v. 29, n. 3, p. I43-I63, 2001 . 